This item was submitted to Loughborough's Research Repository by the author.

Items in Figshare are protected by copyright, with all rights reserved, unless otherwise indicated.

\title{
The effects of transformational leadership on followers' perceived work characteristics and psychological well-being : a longitudinal study
}

PLEASE CITE THE PUBLISHED VERSION

http://dx.doi.org/10.1080/02678370801979430

\section{VERSION}

AM (Accepted Manuscript)

\section{LICENCE}

CC BY-NC-ND 4.0

\section{REPOSITORY RECORD}

Nielsen, Karina, Raymond Randall, Joanna Yarker, and Sten-Olof Brenner. 2019. "The Effects of Transformational Leadership on Followers' Perceived Work Characteristics and Psychological Well-being : A Longitudinal Study". figshare. https://hdl.handle.net/2134/15224. 
This item was submitted to Loughborough's Institutional Repository (https://dspace.lboro.ac.uk/) by the author and is made available under the following Creative Commons Licence conditions.

\section{creative
commons}

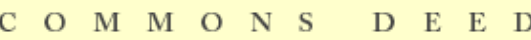

Attribution-NonCommercial-NoDerivs 2.5

You are free:

- to copy, distribute, display, and perform the work

Under the following conditions:

Attribution. You must attribute the work in the manner specified b the author or licensor.

Noncommercial. You may not use this work for commercial purposes.

No Derivative Works. You may not alter, transform, or build upon this work.

- For any reuse or distribution, you must make clear to others the license terms of this work.

- Any of these conditions can be waived if you get permission from the copyright holder.

Your fair use and other rights are in no way affected by the above.

This is a human-readable summary of the Leqal Code (the full license).

\section{Disclaimer 만}

For the full text of this licence, please go to: http://creativecommons.org/licenses/by-nc-nd/2.5/ 
Nielsen, K., Randall, R., Yarker, J. \& Brenner, S-O. (2008). The effects of transformational leadership on followers' perceived work characteristics and well-being: A longitudinal study. Work and Stress, 22, 16-32.

\section{Abstract}

There is some evidence that transformational leadership style is linked to employee well-being at work. However, it is not clear whether this is due to (i) a direct relationship between leadership behaviour and well-being outcomes, or (ii) a relationship between leadership behaviour and wellbeing that is mediated by followers' perceived work characteristics. This paper examines the validity of these two mechanisms using data from a longitudinal questionnaire study of staff within the elderly care sector in a Danish local government. A theory-driven model of the relationships between leadership, work characteristics and well-being was tested using Structural Equation Modelling. The results indicated that followers' perceptions of their work characteristics do mediate the relationship between transformational leadership style and well-being. However, there was only limited evidence of the existence of a direct path between leadership behaviour and employee well-being. These findings have important implications for design, implementation and management of efforts to improve employee well-being.

Keywords: Transformational leadership, well-being, mediation, work characteristics, longitudinal 


\section{Introduction}

The aim of this study is to examine the mechanisms through which transformational leadership behaviour influences employee well-being. It uses a longitudinal study design to test the validity of two mechanisms. In the first mechanism, leadership behaviour has a direct impact on followers' well-being. In the second mechanism, the impact of leadership behaviour on perceived work characteristics mediates the leadership-well-being relationship. To do this the study builds upon the findings of two bodies of well-being research: studies of the influence of i) leadership and ii) work characteristics on employee well-being. The study focuses on transformational leadership style due to its dominant position in high quality leadership research (Bass, 1990; Lowe \& Gardner, 2001; Judge \& Piccolo, 2004).

Transformational leaders can be described as "leaders [who] broaden and elevate the interests of their followers, generate awareness and commitment of individuals to the purpose and mission of the group, and when they enable subordinates to transcend their own self-interests for the betterment of the group" (Seltzer et al., 1989, p. 174). Transformational leaders establish a shared vision through which leaders provide a meaningful and creative basis from where change is brought about in people and contexts (Bass, 1985). The concept is comprised of idealised influence/charisma (the leader acts as a role model and promotes desirable behaviour), inspirational motivation (the leader formulates a clear and attractive vision), intellectual stimulation (the leaders encourages followers to make their own decisions and be creative and innovative) and individualised consideration (the leader acts as a coach and a mentor) (Bass, 1985).

There is a small body of empirical research that has shown a link between leadership style and measures of employee well-being. Bono and llies (2006) found a relationship between charismatic leaders and positive emotions and mood. Gilbreath and Benson (2004) found that supervisory behaviour explained incremental variance over and above other workplace factors when predicting general health. A few studies have examined the relationship between 
transformational leadership and subordinate health and well-being outcomes including measures of burnout (Seltzer, Numerof, \& Bass, 1989), well-being (Arnold, Turner, Barling, Kelloway, \& McKee, 2007) and job-related stress (Sosik, \& Godshalk, 2000). However, all of these studies have been cross-sectional. The only evidence of a causal link between transformational leadership behaviour and follower well-being comes from a longitudinal study by van Dierendonck, Haynes, Borril, and Stride (2004). They also found a reciprocal relationship whereby followers who reported higher levels of well-being also reported their manager had a more active and supportive leadership style over time. This link may exist because leaders' behaviour is likely to provoke emotional responses in subordinates which have implications for their well-being (Druskat, 1994). However, this study did not directly examine the possibility that the relationship between leadership behaviour and well-being might be mediated by the impact of leadership behaviour on followers' perceived work characteristics.

Research on the relationship between transformational leadership and performancerelated outcomes tends to find that followers' perceptions of work characteristics mediate transformational leadership-performance relationships. Psychological empowerment (Avolio, Zhu, Koh, \& Bhatia, 2004; Jung, \& Sosik, 2002), trust and value congruence (Jung, \& Avolio, 2000), cohesiveness and collective efficacy (Jung, \& Sosik, 2002), and goal clarity and support for creative thinking (Nemanich, \& Keller, 2007) have all been found to mediate this relationship. Similar mediation of the relationship between transformational leadership and well-being is also plausible. This is because of the existence of significant associations between i) the perceived work characteristics that can be influenced by leaders such as job demands and control (Cherniss, 1995) and ii) a range of self-report and measures of well-being and general health, and observed health outcomes such as coronary heart disease (Karasek and Theorell, 1990; Bosma, Marmot, Hemingway, Nicholson, Brunner, \& Stansfeld, 1997). Arnold et al, (2007) found in their crosssectional study that perceptions of having a meaningful work mediated the relationship between transformational leadership and well-being. It is possible that these effects also exist over time and for more work characteristics. 
Transformational leaders may have a profound impact on followers' perceptions of their work characteristics because they provide personal attention to promote development through individualized consideration, enable new ways of working, encourage novel problem solving, and provide coaching and encouragement of specific behaviours in subordinates through intellectual stimulation (Bass, 1999, Sashkin, \& Rosenbach, 1993). Some cross-sectional studies do suggest that a link between leadership and well-being may be explained by examining how leadership behaviour affects followers' perceptions of their work characteristics. For example, in studies of workplace control, Cooper and Cartwright (1997) and Offerman and Hellmann (1996) identified that leaders play a significant role in monitoring the amount of control individuals have over their role. They also found, in a separate analysis, that increased delegation and participation were associated with increased levels of well-being. High levels of social support from superiors have also been shown to be associated with lower stress and burnout (Lee and Ashforth, 1996). Both of these work characteristics may be associated with transformational leadership behaviour. Moreover, a recent meta-analysis of longitudinal research (de Lange, Taris, Kompier, Houtman, and Bongers, 2003) has found strong evidence for causal relationships between a number of work characteristics that could be heavily influenced by leaders and health and well-being.

\section{Hypothesised Mediators}

To fully understand how leadership behaviour influences employee well-being, the nature and extent of any mediation by perceived work characteristics needs to be examined. Mathieu, and Taylor (2006) identify three types of mediation that need to be examined: (i) indirect effects, where the independent variable is related to the mediator, and the dependent variable is related to the mediator, but there is no direct relationship between the independent and the dependent variable, (ii) partial mediation where a direct relationship between leadership behaviour and well-being is present together with the mediated effect, and (iii) a fully mediated model where the direct relationship no longer exists after the mediator is introduced into the model. As the relationship between transformational leadership and well-being has previously been established (e.g. van 
Dierendonck et al., 2004) we propose that either the second or the third mechanism will be present in our model.

The nature of transformational leadership behaviour means that specific predictions can be made about the some of the work characteristics that may mediate its relationship to wellbeing. We propose that three work characteristics that may mediate the relationship between transformational leadership behaviour and well-being in followers: increased role clarity, increased meaningfulness and increased opportunities for development.

Increased role clarity

Several specific aspects of leadership behaviour that are defined as 'transformational' may also positively influence followers' perceived role clarity. In setting a clear and attractive vision (inspirational motivation) leaders may help followers to understand the ends to which they are working: the leader formulates clear goals and facilitates the achievement of these e.g. the leader influences followers to focus on some things and not others (Bass, 1990). By displaying a set of clear values and through role modeling (idealised influence) followers can observe how they may themselves take responsibility for own actions and development. For example, it has been found that those who work with leaders exhibiting high standards and expectations feel more comfortable and able to engage in decisions concerning the task at hand (Bass, \& Avolio, 1994). The transformational leader may also influence followers' perceptions of the level of role clarity by i) ensuring that they have the necessary information that is required to work towards the shared vision and ii) giving them knowledge and support to enable them to develop the skills required to analyse the information for themselves (Sofarelli, \& Brown, 1998).

Increased meaningfulness

The definition of transformational leadership identifies a number of aspects of leaders' behaviour which may be linked with followers' perceptions of the meaningfulness of work. Recent studies have reported positive associations between transformational leadership and perceived meaningful 
work (Arnold et al., 2007; Piccolo \& Colquitt, 2006). The transformational leader is described as giving people meaning, purpose and a sense of higher value in their work (Bass, 1990). Beyond that, they are also described as giving people the ability to see beyond the present problems of day-to-day endeavours and provide stimulation to work harder and collectively with others, realizing the meaningful interrelationship of both the vision and their work. Inspirational motivation may be used to formulate a clear vision that allows employees to see the where their work fits in with organisational objectives (Burke, Stagl, Klein, Goodwin, Salas, \& Halpin, 2006), construct a common framework that creates a common sense of purpose (Nemanich, \& Keller, 2007) and to communicate optimism about future goals and provide meaning for the task at hand. By establishing a shared vision, transformational leaders can provide a meaningful and creative basis from where change can occur in people and their work environment (Bass, 1985). The transformational leader is also described as having the ability to find meaning in piecemeal actions and to establish those connections for others enabling them to see the macrolevel while dealing with the microlevel (Sofarelli, \& Brown, 1998).

Increased opportunities for development Several aspects of transformational leadership behaviour may be associated with employees' perceptions of their opportunities to develop. Transformational leaders are often described as constructing organisational contexts that permit followers to exercise and expand their own cognitive abilities, and to become more capable of defining and enacting their own visions independently of the leader's immediate control and supervision (Jung, \& Sosik, 2002; Sashkin, \& Rosenbach, 1993). They may help followers unlearn past routines, develop creative solutions and respond appropriately to new environments (Bass, 1985; Bass, Avolio, Jung, \& Berson, 2003). Through intellectual stimulation, the transformational leader may facilitate follower development by challenging their assumptions, thoughts and imagination (Avolio et al, 2004; Bass et al, 2003). Moreover, transformational leaders may actively encourage followers to take calculated risks, and to seek out opportunities and to solve complex organisational problems. Through inspirational 
motivation leaders can also engage their followers 'above and beyond the call of duty', encouraging them to take charge of their own development at work. (Bass, 1990, Tichy, \& Ulrich, 1984). Furthermore, idealised influence involves the display of clear values, and through role modeling followers can observe how they may themselves take responsibility for own actions and development. Coaching and mentoring may be used to encourage followers to make their own decisions in a supportive environment (Avolio et al, 2004).

Our analysis of how transformational leadership behaviour could impact upon work characteristics suggests that some aspects of leadership behaviours may impact on more than one work characteristic. Furthermore, meaningfulness, role clarity and opportunities for development often co-vary. This means that it may not be possible to identify separate mediating mechanisms for each work characteristic if they were shown to be highly correlated with each other. In such circumstances, the research question would need to be examined using as a mediator a combined measure of these work characteristics.

The Present Study

To our knowledge there have yet not been any longitudinal studies which have investigated whether perceived work characteristics mediate the relationship between leadership behaviour and follower health and well-being. This study aims to build on previous research by testing the following hypothesis:

The causal relationship between leadership and followers' well-being is partially or fully mediated by followers' perceived work characteristics (i.e. role clarity, meaningfulness and opportunities for development).

By using a longitudinal design we examine whether there is evidence of such mediation in both cross-sectional data (i.e. at time 1 and at time 2) and longitudinal data (i.e. in the relationships between time 1 and time 2 measures). 
Data from workers providing care to the elderly is used to test the hypothesis.

Although transformational leadership has been shown to be important in a variety of organisational contexts, both within the private and the public sector (Bass, 1999), it may be of particular importance within the healthcare sector. Healthcare workers are in close contact with the patient and thus they are the first to notice changes in patients' health and can most easily assess the needs of the patient. They often follow the patient over long periods of time and therefore they have an in-depth knowledge of how to address the problems and concerns raised by their patients. Therefore the employees who are encouraged to solve problems and take responsibility are a necessity in healthcare (Corrigan, \& Garman, 1999; Dunham-Taylor, 2000; Morrison, Jones, \& Fuller, 1997). It has been argued that raising employees' exposure to transformational leaders and leadership behaviour is the key to improving healthcare provision in the future (Sofarelli, \& Brown, 1998; Thyer, 2003). Transformational leaders may be particularly important in advancing the development of staff in health care settings since it may encourage staff to find innovative solutions, to extend beyond their boundaries of comfort, and to test new ways of working (Sofarelli, \& Brown, 1998).

2. Method

\subsection{Design and procedure}

The study used a longitudinal questionnaire survey design. Questionnaires were distributed on two occasions to employees with an 18-month interval between them. On both occasions, participants were asked questions about their perceived work characteristics, psychological health and wellbeing and asked to rate their immediate manager (line manager) on a variety of leadership behaviours. Transformational leadership has been shown to operate, and be important, at this managerial level (Bass, 1999). Participants returned their completed questionnaires directly to the research group. 


\subsection{Participants}

The sample consisted of staff working within the elderly care sector for a large Danish local government. In Denmark, the elderly care sector is organised into units where some staff provide care to elderly who are still in their own home and others provide care in elderly care homes. In this sample two units including both types of staff were included (in this sample $51 \%$ of the healthcare staff worked in the homecare and the remainder in the elderly care homes). Although only one human service organisation was included we tried to ensure a variety of settings and job content to examine whether the effects were context-independent. First, two independent centers were included in the study with different management and different cultures (One center was larger than the other and $61 \%$ of staff came from this center). Results of t-tests revealed that there were no significant differences between the two centres and they were in subsequent analyses treated as one. Second, all staff from the centres participated. This presented different groups of staff ranging from cleaning personnel, canteen personnel, healthcare assistants, nurses, physiotherapists, and maintenance staff. All staff had direct contact with clients. Staff were organised in groups, e.g. home care staff covering a geographical area or staff covering a nursing home would constitute a group, each group had a formal leader with managerial responsibilities; this was the manager they were asked to rate. At time 1, questionnaires were distributed to 551 staff and 447 questionnaires were returned yielding a response rate of $81 \%$ for time 1 analysis. $93 \%$ were female, the average age was $44(S D=11.13)$, and they had been working in their current workplace for 12 years on average. The majority of staff were healthcare assistants (62\%), $12 \%$ were nurses, $18 \%$ had other health-related educations and the remaining $8 \%$ had no healthcare-related education. At time 2 the questionnaire was distributed to 521 staff and 274 returned the questionnaire, yielding a response rate of $53 \%$ for time 2 analysis. Surveys were sent to all employees working at the centers and thus new staff was included in the second round of the survey. $91 \%$ were female, the average age was $45(S D=10.93)$, and they had been working in their current workplace for 7 years on average. The majority of staff were healthcare assistants (65\%), $10 \%$ were nurses, $19 \%$ had other health-related educations and the remaining $6 \%$ had no healthcare-related education. 
188 participants provided data at both time 1 and time 2 . Of these, $93 \%$ were female. The mean age was $45(S D=9.90)$ and they had in average been 9 years at the workplace (at time 1$)$. The majority of staff were healthcare assistants (61\%), $12 \%$ were nurses, $21 \%$ had other health-related educations and the remaining $8 \%$ had no healthcare-related education. This sample is representative of the $\mathrm{T} 1$ and $\mathrm{T} 2$ samples.

\subsection{Measures}

Transformational leadership was measured using the Global Transformational Leadership Scale developed by Carless, Wearing, and Mann (2000). It consists of seven items and has been found to have a high degree of convergent validity with more established and lengthier questionnaires such as the MLQ and the LPI (Carless et al., 2000). Examples of item are: "My leader communicates a clear and positive vision of the future", "My leader gives encouragement and recognition to staff" and "My leader encourages thinking about problems in new ways and questions assumptions". Response categories were: $1=$ To a very large extent, $2=$ To a large extent, 3 = Somewhat, $4=$ To a small extent, $5=$ To a very small extent. Cronbach's alpha at time 1 was .90 , and .94 at time 2 .

Scales measuring the possible mediating variables (role clarity, meaningful work, opportunities for development) and well-being were all taken from the COpenhagen PsychoSOcial Questionnaire (COPSOQ; Kristensen, Borg \& Hannerz, 2002; Kristensen, Hannerz, Hogh \& Borg, 2006). These scales have been used in a number of studies and have been found to show good reliability and validity (Aust, Rugulies, Skakon, Scherzer, \& Jensen, 2005; Borritz, Rugulies, Bjorner, Villadsen, Mikkelsen, \& Kristensen, 2006; Lund, Labriola, Christensen, Bültmann, Villadsen, \& Burr, 2006; Nielsen, Rugulies, Christensen, Smith-Hansen, \& Kristensen, 2006). The scales are relatively short (thus helping to protect response rates) and provide adequate measures multi-faceted constructs. Within this data set the reliabilities of the scales were acceptable when compared to the level of 
reliability typically found for other, longer, measures of these constructs.

Role clarity (3 items). This measured the degree to which employees reported that they knew their roles and responsibilities. An example of an item is: "Does your work have clear objectives?'. Response categories were: 1 = To a very large extent, $2=$ To a large extent, $3=$ Somewhat, $4=$ To a small extent, $5=$ To a very small extent. Cronbach's alpha at time 1 was .59 , and .75 at time 2.

Meaningful work (3 items). This scale was based on the work of Hackman and Oldham (1980). Employees were asked to rate the degree to which they experienced their jobs to be meaningful and their work was part of a greater whole. An example of an item is: "Do you feel that the work you do is important?'. Response categories were: 1 = To a very large extent, $2=$ To a large extent, $3=$ Somewhat, 4 = To a small extent, $5=$ To a very small extent. Cronbach's alpha at time 1 was .66 , and .63 at time 2.

Opportunities for development (4 items). This scale examined the degree to which employees reported having the opportunities to develop new skills and grow in their job. An example of an item is: "Does your work require you to take the initiative". Response categories were: $1=$ To a very large extent, $2=$ To a large extent, $3=$ Somewhat, $4=$ To a small extent, $5=$ To a very small extent. Cronbach's alpha at time 1 was .76 , and .59 at time 2.

Well-being (5 items). This scale measured the degree to which employees been in a positive state of mind, e.g. happy and vivacious. An example of an item is: "Have you over the past two weeks felt active and energetic?' Response categories were: $1=$ All the time, $2=$ Most of the time, $3=A$ bit more than half of the time, $4=A$ bit less than half of the time, $5=$ Only a little of the time, $6=$ Not at all. Cronbach's alpha at time 1 was .87 , and .85 at time 2. 
As all outcomes were measured on different scales, these were transformed to standardized scales so they ranged from 0-100 with 100 representing a high score on the construct. For scales with five response categories, responses were transformed such that $1=0,2=25,3=50,4=75$, $5=100$. This was done to enhance clarity in the interpretation and meaning of the results. This standardisation does not impact on the relationship between variables and thus does not influence the covariance matrix on which the analyses are based.

\subsection{Analysis}

Testing T1, T2, and Time 1 to Time 2.

The mediating effect of work characteristics were tested using structural equation modelling (SEM) with pairwise deletion (LISREL 8.7, Jöreskog \& Sörbom, 1999). Scale scores were used as indicators for each construct in the models. We accounted for the effects of measurement error by fixing the value of the unique variance indicator to be one minus the reliability multiplied by the scale variance (Niehoff \& Moorman, 1993, Sinclair, Martin, \& Croll, 2002, Lim, 2003). As the three different kinds of work characteristics were found to correlate and we assume they exert the same mediating mechanism we decided to create a factor covering all three characteristics. We call this scale work characteristics.

To confirm the proposed three-factor structure of our measures we tested a measurement model including our measures: transformational leadership, perceived work characteristics (combined in one variable) and well-being. This was done to confirm whether our three work characteristics: meaningfulness, role clarity and opportunities for development could be meaningfully combined in one scale. The measurement model provided a good fit to the data, $\chi^{2}=$ $(845, N=542)=1715.26$, RMSEA $=.045$. This confirmed that the three work characteristics could be combined in one scale in further analyses. 
Mediation effects were tested in three ways: at time 1, at time 2 (synchronous effects) and between time 1 and 2 (i.e. temporal causality). Temporal mediation may occur through two possible one-step mechanisms: Transformational leadership T1 influences work characteristics T2 which in turn is related to well-being at time 2 , or Transformational leadership at time 1 is related to work characteristics T1 which in turn influences well-being at time 2. However, temporal mediation may also occur through at two-step mechanism: Transformational leadership T1 is related to work characteristics at T1 which influences work characteristics at T2 which in turn are associated with employee well-being at T2.

The maximum likelihood method of parameter estimation was used with the covariance matrix as input. First, we tested the stability of our measures over time (Stability Model) by regressing time 2 transformational leadership over time 1 transformational leadership, with the same procedure used to examine the stability of perceived job characteristics and wellbeing measures.

We tested the mediating mechanism of work characteristics through four models. A full mediation model (M1) was tested that assumed that the direct relationships previously found in research would not be present because of the mediating effects of followers' perceptions of their work characteristics.

To test for partial mediation we tested three different partial mediation models: First, we tested synchronous partial mediation at time 1 by including a direct path between transformational leadership T1 and well-being T1 (M2). Next, we tested synchronous partial mediation at time 2 including a direct path from transformational leadership T2 to well-being T2 (M3). Finally, we also explored partial mediation over time (M4). We included a direct path from transformational leadership T1 to well-being T2. Based on the findings by van Dierendonck et al (2004) that there could be a reciprocal relationship between well-being and transformational leadership, a path between time 1 well-being and time 2 transformational leadership was included in the model. See figure 1 for an overview of the tested models. 
Insert figure 1 around here

M1 serves as a baseline model against which the other, more complex, models (M2, M3, M4) are examined to see if they offer significant gains in explanatory power. Comparison of M1 to other models will reveal which model accounts best for the data. A model is considered to fit the data better than a rival model if the $\chi^{2}$ value is significantly lower $(p<.05)$ than that of the one to which it was compared. The acceptable levels of fit used to assess the adequacy of each model were according to the recommendations made by Marsh, Balla, and McDonald (1988), Brown, and Cudek (1993) and Anderson, and Gerbing (1988)).

\section{Results}

\subsection{Preliminary analyses}

Table 1 displays the scales, means, standard deviations, scale reliabilities, and intercorrelations of all variables in this study. All measures relevant to our mediation models were significantly correlated i.e. measures of transformational leadership, the hypothesised mediating variables and employee well-being were correlated at both time 1 and time 2, and between time 1 and time 2 . This calls for further analyses of the interrelationships between transformational leadership, perceived work characteristics and well-being.

\section{Insert table 1 around here}

Next, we tested whether measures were stable over time. The results of the Stability Model indicated strong relationships between transformational leadership at time 1 and time $2(\beta=.50 p$ $<.001)$, work characteristics at time 1 and time $2(\beta=.56 p<.001)$, and well-being at time 1 and time $2(\beta=.60 p<.001)$. However, the overall model presented a poor fit to the data indicating that 
further relationships existed across the constructs; this was also confirmed by modification indices that suggested further relationships.

\subsection{Testing the hypotheses}

The first fully mediated model (Model 1) testing the mediating mechanism of perceived work characteristics revealed a good fit to the data. AGFI, CFI, and NNFI were all above the recommended level of .90 , but the RMSEA was .04 , below the recommended .05 for a good model.

Second, we tested for partial mediation at time 1 by including a direct path from transformational leadership time 1 to well-being at time 1 (M2). This model also presented a good fit to the data. CFI, AGFI and NNFI were all well above .90 and the RMSEA was .00 . The $\Delta \chi^{2}(2)=$ $7.28, p>.05$ revealed a significantly better fit to the data than did the fully mediated model.

We then went on to test the third model (M3) exploring the synchronous partial mediation of work characteristics at time 2. Model fit revealed a good fit to the model: CFI, AGFI and NNFI were all above the recommended .90 and the RMSEA was .40 . However, the model did not prove to represent a better fit to the data; $\Delta \chi^{2}(1)=1.26, p<.05$.

Finally, we went on to test for partial mediation over time (M4). This model also revealed a good fit to the data. CFI, NNFI, and AGFI were all above. 90 and the RMSEA was .05. However, this model did not represent a significantly better fit to our baseline model (M1); $\Delta \chi^{2}(1)$ $=.35, \mathrm{p}<.05$.

Although all models showed a good fit to the data, in the following we discuss M2 (partial mediation at time 1) because it was the best fit to the data: it represented a better fit when comparing the $\chi^{2}$, the RMSEA was better that those of the other models and because inspection of the paths testing partial mediation at time 2 and over time showed these to be non-significant. 
Insert table 2 around here

In figure 2, the partially mediating model with the best fit is reported (M2). It provides an overview of the direct and mediated relationships between transformational leadership and well-being as well as the reciprocal relationship between transformational leadership and well-being. For all constructs, time 2 measures were influenced by the baseline level. The hypothesised mediating effect of work characteristics was confirmed, both synchronously and over time through a two-step mechanism (with time 1 and time 2 measures of the work characteristics involved in the mediating mechanism). A direct path existed between transformational leadership and well-being at time 1; indicating partial mediation. However, this partial mediation was neither found at time 2 nor over time. Transformational leadership at time 1 was related to work characteristics at time 1 . The time 1 work characteristics all predicted the time 2 work characteristics, which in turn were related to well-being at time 2. Thus the mediating mechanism operated through the followers' perceptions of the work characteristics both at time 1 and time 2. Further, a slight negative relationship was found between work characteristics T1 and well-being at T2.

Insert figure 2 around here

\section{Discussion}

This study aimed to enhance the understanding of the previously established link between transformational leadership and well-being. We found support for our hypotheses: followers' experience of a meaningful work environment, role clarity and opportunities for development partially mediated the relationship between transformational leadership and followers' well-being. This relationship was confirmed at three levels. First, although there was a direct link between transformational leadership at time 1 and well-being at time 1, work characteristics at time 1 also partially mediated this relationship. In the same way, work characteristics at time 2 fully mediated the relationship between transformational leadership and well-being at time 2 . Perhaps most 
importantly, our results showed that transformational leadership behaviour at time 1 was related to employee well-being at time 2 , through a relatively complex mechanism. The work characteristics at time 1 and time 2 were found to form a 2-stage mediating mechanism for the relationship between transformational leadership at time 1 and well-being at time 2. No direct relationship was found between between transformational leadership at T1 and well-being at T2. The absence of a direct link over time casts doubt on whether transformational leadership behaviour can cause changes in employee well-being unless it results in changes in perceived work characteristics. Our results strongly indicate that transformational leadership is closely related to the perception of some aspects of the work characteristics of followers, and that previous studies which have suggested a direct relationship (e.g. Dunham-Taylor, 2000; Seltzer et al, 1989; Shieh, Mills, \& Waltz, 2001; Sosik \& Godshalk, 2000) may have underestimated the importance of the mediating effects of followers' perceived work characteristics. However, the existence of a direct effect cannot be entirely discounted: some behaviours may provoke an automatic emotional response in followers that is independent of work characteristics (Druskat, 1994). However, our research suggests that this relationship is not robust over an extended period of time.

Our results also supported the reciprocal nature of the relationship between the managers' perceived transformational leadership style and well-being (Van Dierendonck et al, 2004). In all four models we found a significant relationship between time 1 well-being and time 2 transformational leadership. This supports the notion that the followers' level of self-reported wellbeing also influences the reporting of leadership behaviour i.e. it establishes a 'feedback loop' linking employee well-being and leader behaviour. This may occur for two reasons. The first reason is that employees with poor well-being may find it hard to engage in activities encouraged by the transformational leader: engaging in independent decision making and problem solving. Thus leaders may find it hard to lead the way and make employees perform 'beyond the call of duty' if they have no energy and engagement in work. On the other hand employees with high levels of energy and enthusiasm may encourage managers to take the lead, create a vision and 
make an effort to develop his or her employees. This gives rise to the second possible reason: employees experiencing poor well-being may perceive their leaders' behaviour in a negative way perceiving the leader to be unsupportive, even if the manager does engage in transformational leadership behaviours.

\subsection{Limitations}

Some limitations should be considered when interpreting our results. The transformational leadership paradigm provides a useful, but not exhaustive account of leadership style. Our study used a broad, but reliable and valid measure of transformational leadership to test the validity of mediated relationships. The measure chosen was well-suited to a study population that had few academic educational qualifications: it was feared that a lengthy questionnaire would adversely influence response rates without leading to substantial gains in reliability and validity. There has been a debate as to whether research should use uni-dimensional scales of transformational leadership. It has been recommended to use one single scale of transformational leadership for research purposes as the subcomponents are highly inter-correlated (Bass, 1999; Judge \& Piccolo, 2004). However, in future research is would be interesting to examine whether the subcomponents of transformational leadership are similarly mediator whether any exhibit direct effects on well-being (e.g. by provoking a strong and long-lasting emotional response among followers). Of course, training needs analysis may suggest that for training purposes it may be more desirable to focus on the measurement and development of specific sub-components of transformational leadership.

It is also possible that transformational leadership influences a much wider range of perceived work characteristics than the ones included in our study. However, the aim of this paper was to test for the existence of mediation with a sample of different perceived work characteristics that can be argued to be directly influenced by transformational leadership: it is important that future research examines whether other work characteristics also act as mediators. Furthermore, 
future research is also needed to tease apart the specific mediating role played different work characteristics (e.g. in work environments where role clarity does not co-vary with meaningfulness)

\subsection{Implications for practice}

The results indicate the importance of making managers aware of the degree to which they influence the followers' perceptions of work characteristics and self-reported well-being. Exerting behaviours associated with transformational leadership (such as stimulating employees to engage in complex decision making and problem solving, providing a clear vision, coaching and mentoring individuals etc) may increase the well-being of their followers but only if their behaviour alters the way followers perceive their work. This, in turn, may support the manager in exerting these kinds of behaviour through the feedback loop suggested by our results. The results also have important implications for those aiming to implement organisational-level interventions to improve employee health and well-being. The longitudinal nature of our study indicates that it is likely that by training leaders to exert certain behaviours it may possible to change work characteristics. Rather than implementing wide-ranging organisational-level changes to job design and work organisation of followers' work, these results suggest that training their superiors may have a similar impact. For example, training managers in transformational leadership behaviours may bring about higher levels of involvement for followers who also perceive their job as meaningful and experience high levels of influence. Training managerial employees may prove to be both more cost-effective and easy to control than implementing wide-ranging organisational changes to improve the working environment. Previous studies have confirmed that transformational leadership behaviours can be trained (Barling, Weber, \& Kelloway, 1996; Parry, \& Sinha, 2005). However, we need to emphasise that transformational leadership should not be seen as a substitute for poor job design. Transformational leadership should support the re-design of jobs in promoting health and wellbeing at work (Podsakoff, MacKenzie, \& Bommer, 1996).

Our results also indicate that when evaluating the impact of leadership training, organisations should seek to observe changes in leadership behaviour (e.g. by gathering data from 
subordinates about their perceived work characteristics), and not just by examining changes in leaders' knowledge and attitudes. Unless it is accompanied by behaviours that impact on employees' perceived work characteristics, increases in knowledge of transformational leadership are unlikely to result in improvements in employee well-being.

\subsection{Conclusion}

This study highlights two new and important implications for research and practice. First, the study has drawn together important research concepts from two separately researched areas of occupational health psychology literature. It is proposed that through combining research into leadership and work characteristics new advances in understanding how to manage well-being may be realized. Future research would benefit from developing the framework by further combining i) leadership and well-being research and ii) perceived work characteristics and wellbeing research. Considering work characteristics in the absence of studying leadership behaviour (or vice versa) may reveal an incomplete picture of the impact of work and work relationships on well-being. Second, also important is the reciprocal relationship over time between well-being and transformational leadership styles. Employees with poor well-being may either make it difficult for the manager to exert transformational leadership behaviours or may have difficulties benefiting from these behaviours as they appraise the managers' behaviour in a negative manner. Third, the findings have important implications for intervention research. For example, work design interventions focused on role clarity may benefit from the consideration of training managers to exert transformational leadership behaviours. Employing a systemic view on interventions training managers may improve followers' well-being through the creation of a meaningful job that provides role clarity and promotes opportunities to develop. 


\section{References}

Anderson, J.C., \& Gerbing, D.W. (1988). Structural equation modelling in practice: a review and recommended two-step approach. Psychological Bulletin, 103, 411-423.

Arnold, K., Turner, N., Barling, J., Kelloway, E.K., \& McKee, M. C. (2007). Transformational leadership and psychological well-being: The mediating role of meaningful work. Journal of Occupational Health Psychology, 12, 193-203.

Aust, B., Rugulies, R., Skakon, J., Scherzer, T. \& Jensen, C. (2005). Psychosocial work environment of hospital workers: Validation of a comprehensive assessment scale [Electronic version]. International Journal of Nursing Studies, 14.

Avolio, B., Zhu, W., Koh, W., \& Bhatia, P. (2004). Transformational leadership and organizational commitment: Mediating role of psychological empowerment role and moderating role of structural distance. Journal of Organizational Behavior, 25, 951-968.

Barling J, Weber T, Kelloway K. (1996). Effects of transformational leadership training on attitudinal and financial outcomes: A field experiment. Journal of Applied Psychology, 81, 827-832.

Bass, B. M. (1985). Leadership beyond expectations. New York: Free Press.

Bass, B.M. (1990). Bass and Stogdill's handbook of leadership. New York: Free Press.

Bass, B. M. (1999). Two decades of research and development in transformational leadership. European Journal of Work and Organizational Psychology, 8, 9-32.

Bass, B.M., \& Avolio, B. J. (1994). Improving organizational effectiveness through transformational leadership. Thousand Oaks, CA: Sage.

Bass, B. M., Avolio, B.J., Jung, D.I., \& Berson, Y. (2003). Predicting unit performance by assessing transformational and transactional leadership. Journal of Applied Psychology, 88, 207-218.

Bono, J.E., \& llies, R. (2006). Charisma, positive emotions and mood contagion. Leadership Quarterly, 17, 317-334.

Borritz, M., Rugulies, R., Bjorner, J.B., Villadsen, E. Mikkelsen, O.A. \& Kristensen, T.S. (2006). Burnout among employees in human service work: design and baseline findings of the PUMA Study. Scandinavian Journal of Public Health, 34, 49-58.

Bosma, H., Marmot, M., Hemingway, H., Nicholson, A., Brunner, E., \& Stansfeld, S. (1997). Low job control and risk of coronary heart disease in Whitehall II (prospective cohort study). British Medical Journal, 314, 558-565.

Brown, M. W., \& Cudek, R. (1993). Alternative ways of assessing model fit. In K. Bollen, \& J.S. Long (Eds). Testing structural equation models (136-162). Newbury Park, CA: Sage. 
Burke, C. S., Stagl, K., Klein, C., Goodwin, G.F., Salas, E., \& Halpin, S.M. (2006). What type of leadership behaviors are functional in teams? The Leadership Quarterly, 17, 288-307.

Carless, S., Wearing, A., \& Mann, L. (2000). A short measure of transformational leadership. Journal of Business and Psychology, 14, 389-405.

Cherniss, C. (1995). Beyond burnout: Helping teachers, nurses, therapists \& lawyers recover from stress \& disillusionment. New York: Routledge.

Cooper, C.L., \& Cartwright, S. (1997). An intervention strategy for workplace stress. Journal of Psychosomatic Research, 43, 7-16.

Corrigan, P., \& Garman, A. (1999). Transformational and transactional leadership skills for mental health teams. Community Mental Health Journal, 35, 301-312.

de Lange, A.H., Taris, T.W., Kompier, M.A.J., Houtman, I.L.D., \& Bongers, P.M. (2003). The very best of the millennium: Longitudinal research and the demand-control-(support) model. Journal of Occupational Health Psychology, 8, 282-305.

Druskat, V. U. (1994). Gender and leadership style: transformational and transactional leadership in the Roman Catholic Church. Leadership Quarterly, 5, 99-119.

Dunham-Taylor, J. (2000). Nurse executive transformational leadership found in participative organizations. Journal of Nursing Administration, 30, 241-250.

Gilbreath,B., \& Benson, P.G. (2004). The contribution of supervisor behavior to employee psychological well-being. Work \& Stress, 18, 255-266.

Hackman, J.R., \& Oldham, G.R. (1980). Work redesign. Reading, MA: Addison- Wesley. Jöreskog, K.G., \& Sörbom, D. (1999). LISREL 8.3: Users reference guide. Lincolnwood, IL: Scientific Software International.

Judge, T., \& Piccolo, R.F. (2004). Transformational and transactional leadership: A meta-analytic review of their relative validity. Journal of Applied Psychology, 89, 755-768.

Jung, D.I., \& Avolio, B.J. (2000). Opening the black box: an experimental investigation of the mediating effects oftrust and value congruence on transformational and transactional leadership. Journal of Organizational Behavior, 21,949-964. 
Jung, D.I., \& Sosik, J.J. (2002). Transformational leadership in groups: The role of empowerment, cohesiveness, and collective effectiveness. Small Group Research, 33, 313-336.

Karasek, R., \& Theorell, T. (1990). Healthy work. New York: Basic Books.

Kristensen, T., Borg, V., \& Hannerz, H. (2002). Socioeconomic status and psychosocial work environment: results from a Danish national study. Scandinavian Journal of Public Health, 30, 41-48.

Kristensen, T., Hannerz, H., Hogh, A., \& Borg, V. (2006). The Copenhagen Psychosocial questionnaire (COPSOQ). A tool for the assessment and improvement of the psychosocial work environment. Scandinavian Journal of Work and Environmental Health, 31, 438-449.

Lee, R.T., \& Ashforth, B.E. (1996). A meta-analytic examination of the correlates of the three dimensions of job burnout. Journal of Applied Psychology, 81, 123-133.

Lim, V.K.G. (2003). Managing HIV at the workplace: An empirical study of HIV and HR managers in Singapore. Journal of Occupational Health Psychology, 8, 235-246.

Lowe, K. B. \& Gardner, W. L. (2001). Ten years of the leadership quarterly: Contributions and challenges for the future. Leadership Quarterly, 11, 459-514.

Lund, T., Labriola, M., Christensen, K. B., Bültmann, U., Villadsen, E., Burr, H. (2006) Psychosocial Work Environment Exposures as Risk Factors for Long-Term Sickness Absence Among Danish Employees: Results From DWECS/DREAM. Journal of Occupational and Environmental Medicine. 47,1141-1147.

Marsh, H., Balla, J., \& McDonald, R. (1988). Goodness-of-fit indexes in confirmatory factor analysis: The effect of sample size. Psychological Bulletin, 103, 391-410.

Mathieu, J.E., \& Taylor, S.R. (2006). Clarifying conditions and decision points for mediational type inferences in Organizational Behavior. Journal of Organizational Behavior, 27, 1031-1056.

Morrison, R., Jones, L., Fuller, B. (1997). The relation between leadership style and empowerment on satisfaction of nurses. Journal of Nursing Administration, 27, 27-34.

Nemanich, L.A., \& Keller, R.T. (2007). Transformational leadership in an acquisition: A field study of employees. Leadership Quarterly, 18, 49-68. 
Niehoff, B.P., \& Moorman, R.H. (1993). Justice as a mediator of the relationship between methods of monitoring and organizational citizenship behaviour. Academy of Management Journal, 36, 527-556.

Nielsen, M. L., Rugulies, R., Christensen, K. B., Smith-Hansen, L., \& Kristensen, T. S. (2006). Psychosocial work environment predictors of short and long spells of sickness absence during a two-year follow-up. Journal of Occupational and Environmental Medicine, 48, 591595.

Offerman, L. R., \& Hellmann, P.S. (1996). Leadership behvior and subordinate stress: A $360^{\circ}$ view. Journal of Occupational Health Psychology, 1, 382-390.

Parry, K. W, Sinha, P.N. (2005). Researching the trainability of transformational organisational leadership. Human Resource Development International, 8,165-183.

Piccolo, R.F., \& Colquitt, J.A. (2006). Transformational leadership and job behaviors: The mediating role of core job characteristics. Academy of Management Journal, 49, 327-340.

Podsakoff, P.M., MacKenzie, S.B., Bommer, M. (1996). Transformational leader behaviors and substitutes for leadership as determinants of employee satisfaction, commitment, trust and organizational citizenship behavior. Journal of Management, 22, 259-298.

Sashkin, M., \& Rosenbach, W. (1993). A new leadership paradigm. In Rosenbach (Ed.). Contemporary issues in leadership (pp. 87-108). Westview Press.

Seltzer, J., Numerof. R., \& Bass, B. (1989). Transformational leadership: Is it a source of more burnout and stress? Journal of Health and Human Resources Administration, 174-185.

Shieh, H.-L., Mills, M.E., \& Waltz, C.E. (2001). Academic leadership style predictors for nursing faculty job satisfaction in Taiwan. Journal of Nursing Education, 40, 203-209.

Sinclair, R.R., Martin, J.E., \& Croll, L.W. (2002). A threat-appraisal perspective on employees' fears about antisocial workplace behaviour. Journal of Occupational Health Psychology, 7, 37-56.

Sofarelli, D., \& Brown, D. (1998). The need for nursing leadership in uncertain times. Journal of Nursing Management, 6, 201-207.

Sosik, J., \& Godshalk, V. (2000). Leadership styles, mentoring functions received, and job-related stress: a conceptual model and preliminary study. Journal of Organizational Behavior, 21, 365-390. 
Thyer, G. (2003). Dare to be different: transformational leadership may hold the key to reducing nursing shortage. Journal of Nursing Management, 11, 73-79.

Tichy, N.M., \& Ulrich, D.O. (1984). SMR Forum: The leadership challenge - A call for the transformational leader. Sloan Management Review, 26, 59-67.

Van Dierendonck, D., Haynes, C., Borril, C., \& Stride, C. (2004). Leadership behavior and subordinate well-being. Journal of Occupational Health Psychology, 9, 165-175. 
Table 1

Intercorrelations Between Scales

\begin{tabular}{|c|c|c|c|c|c|c|c|c|c|}
\hline Scale & $\begin{array}{l}\text { M } \\
(\mathrm{T} 1)\end{array}$ & $\begin{array}{l}\text { SD } \\
(\mathrm{T} 1)\end{array}$ & $\begin{array}{l}\text { M } \\
\text { (T2) }\end{array}$ & $\begin{array}{l}\text { SD } \\
\text { (T2) }\end{array}$ & 1. & 2. & 3. & 4. & 5. \\
\hline 1. Transformational Leadership & 3.00 & 1.03 & 3.08 & 1.01 & $.48^{* *}$ & $.38^{* *}$ & $.16^{*}$ & $31^{* *}$ & $.27^{* \star}$ \\
\hline 2. Role clarity & 2.42 & 0.97 & 3.63 & 0.67 & $.25^{* *}$ & $54^{* *}$ & $.21^{* *}$ & $.32^{* *}$ & $.30^{* *}$ \\
\hline 3. Meaningful work & 3.83 & 0.69 & 3.82 & 0.63 & $.25^{\star *}$ & $.49^{* *}$ & $41^{* *}$ & $.52^{\star *}$ & $.36^{* *}$ \\
\hline 4. Opportunities for development & 2.85 & 0.84 & 3.57 & 0.67 & $.41^{* *}$ & $.53^{\star *}$ & $.51^{* *}$ & $45^{\star *}$ & $.27^{* *}$ \\
\hline 5. Well-being & 3.32 & 0.86 & 3.38 & 0.79 & $.27^{* *}$ & $.30^{* *}$ & $.36^{* *}$ & $.34^{* *}$ & $.53^{\star *}$ \\
\hline
\end{tabular}

Note. Correlations below the diagonal are from time 1 and above the diagonal from time 2. Correlations in the diagonal are between time 1 and time 2. ${ }^{*} p<.05,{ }^{* *} p<.01$ 
Table 2

Fit Indices for Nested Sequence of Longitudinal Models

\begin{tabular}{lllllll}
\hline Model & $\chi 2$ & $\mathrm{df}$ & NNFI & CFI & AGFI & RMSEA \\
\hline Stability Model & 108.41 & 9 & .81 & .89 & .86 & .14 \\
\hline Work characteristics & & & & & & \\
\hline M1:Full mediation model & 8.65 & 5 & 1.00 & 1.00 & .98 & .04 \\
M2: Partial mediation model T1-T1 & 2.07 & 4 & 1.00 & 1.00 & 1.00 & .00 \\
M3: Partial mediation model T2-T2 & 7.39 & 4 & .99 & 1.00 & .98 & .04 \\
M4: Partial mediation model T1-T2 & 8.30 & 4 & .98 & 1.00 & .87 & .05
\end{tabular}

Note. $\mathrm{NNFI}=$ nonnormed fit index; $\mathrm{AGFI}=$ adjusted goodness of fit index, CFI = comparative fit index;

RMSEA = root-mean-square error of approximation. 
Figure 1: Theoretical model 


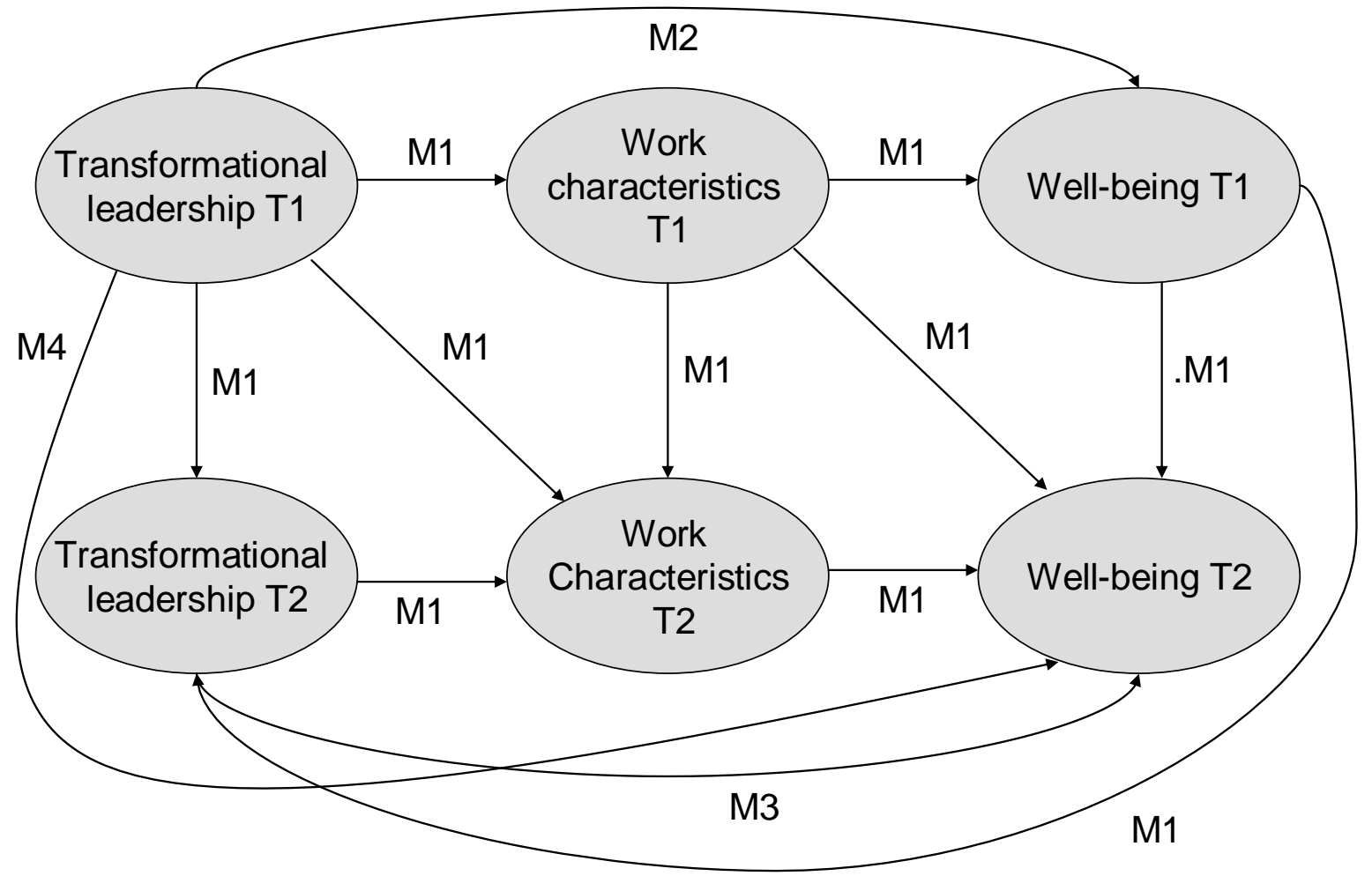

M1 tests full mediation, while M2, M3, and M4 test various partial mediation models 
Figure 2: Standardized maximum likelihood estimates for M2 


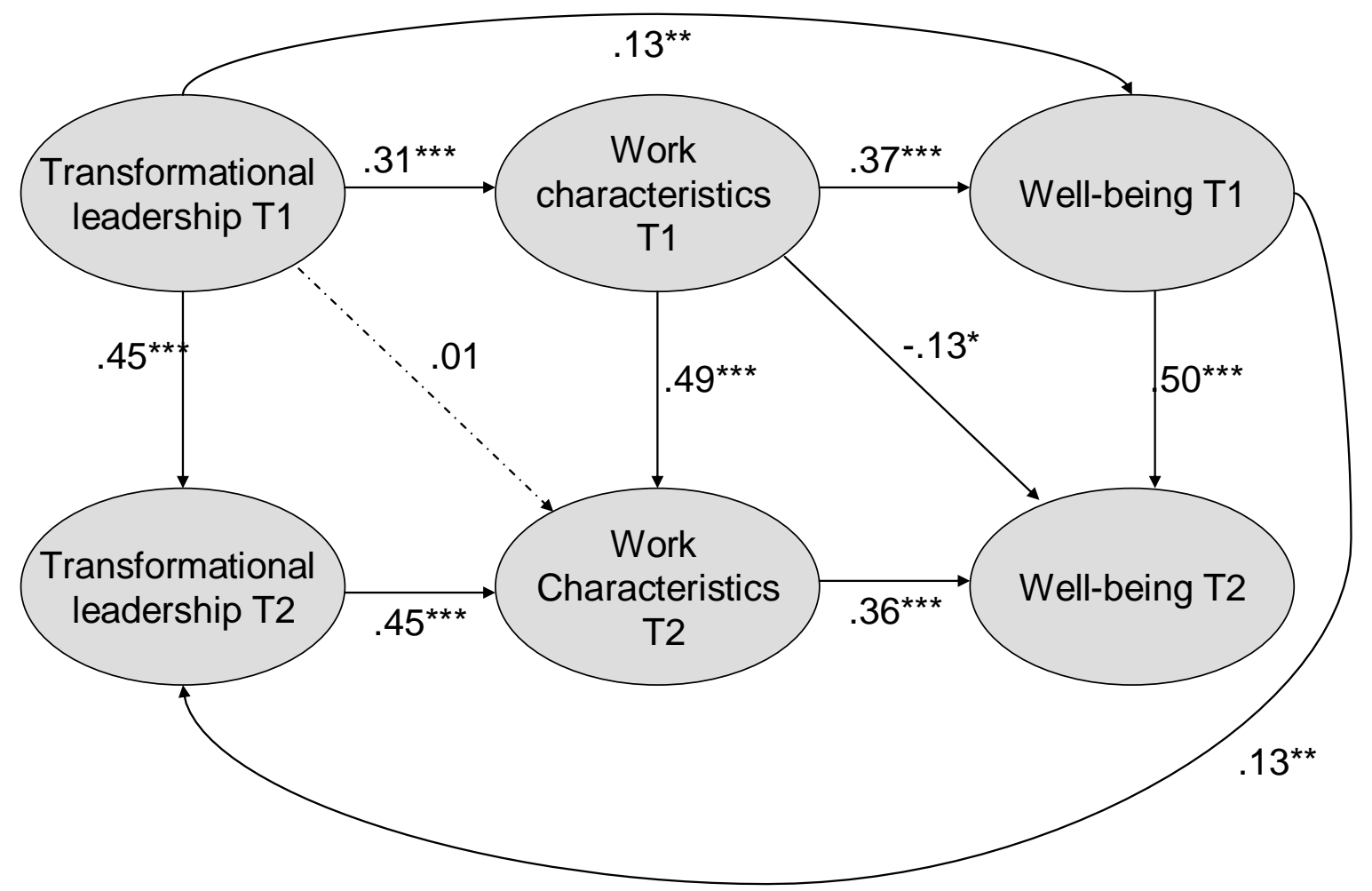

${ }^{*} \mathrm{p}<.05 ;{ }^{* *} \mathrm{p}<.01 ;{ }^{*}<.001$. Dotted lines represent non-significant relationships 
